\title{
Subpleural curvilinear shadow of eosinophilic pneumonia simulating pneumothorax
}

\author{
So HATTORI ${ }^{1}$ (ID) \\ Yuika SASATANI ${ }^{2}$ (ID) \\ Hiroaki SATOH ${ }^{2}$ (ID)
}

\author{
${ }^{1}$ Division of General Medicine, University of Tsukuba, Mito Medical \\ Center-Mito Kyodo General Hospital, Mito, Japan \\ ${ }^{1}$ Tsukuba Üniversitesi, Mito Tıp Merkezi-Mito Kyodo Genel Hastanesi, \\ Genel Tıp Bölümü, Mito, Japan \\ 2 Division of Respiratory Medicine, Mito Medical Center, \\ University of Tsukuba, Mito, Japan \\ ${ }^{2}$ Tsukuba Üniversitesi Mito Tıp Merkezi, Solunum Tıbbı Bölümü, \\ Mito, Japonya
}

Cite this article as: Hattori S, Sasatani $Y$, Satoh $H$. Subpleural curvilinear shadow of eosinophilic pneumonia simulating pneumothorax. Tuberk Toraks 2021;69(4):569-571.

\section{Yazışma Adresi (Address for Correspondence)}

\section{Dr. So HATTORI}

Division of General Medicine,

University of Tsukuba, Mito Medical

Center-Mito Kyodo General Hospital

MITO - JAPAN

e-mail: hirosato0809@yahoo.co.jp

\footnotetext{
CCopyright 2021 by Tuberculosis and Thorax.
}

Available on-line at www.tuberktoraks.org.com
To the Editor,

Subpleural curvilinear opacities that appear along the pleura may resemble linear shadows of the visceral pleura found in pneumothorax (1-4). On plain radiographs, it can be difficult to distinguish between the subpleural curvilinear opacities and the linear shadow representing the visceral pleura observed in pneumothorax. As observed in the present case, although rare, patients with eosinophilic pneumonia can have such subpleural curvilinear opacities. A 72-year-old woman suspected of having eosinophilic pneumonia was referred to our hospital. Chest radiography taken on the day of bronchoscopy showed a curvilinear line at the lateral zone of the right lung (Figure 1A). There was no decrease in oxygen saturation, but pneumothorax had to be differentiated. We performed chest CT scan. However, it revealed the absence of pneumothorax; the curvilinear line in the lung field mimicking pneumothorax was revealed (Figure 1B-C). Bronchoscopy confirmed an increase in eosinophils in the alveolar region, and the patient was diagnosed as having eosinophilic pneumonia. Oral predonisolone $(0.5 \mathrm{mg} / \mathrm{kg} /$ day $)$ was started, and gradually reduced to $2.5 \mathrm{mg} /$ day. The subpleural curvilinear shadows disappeared on a plain radiograph two months after the start of treatment (Figure 1-D). Thereafter, eosinophilic pneumonia does not recur.

In eosinophilic pneumonia, ground glass shadows and consolidation are found in the peripheral lungs. Usually, the opacities are 


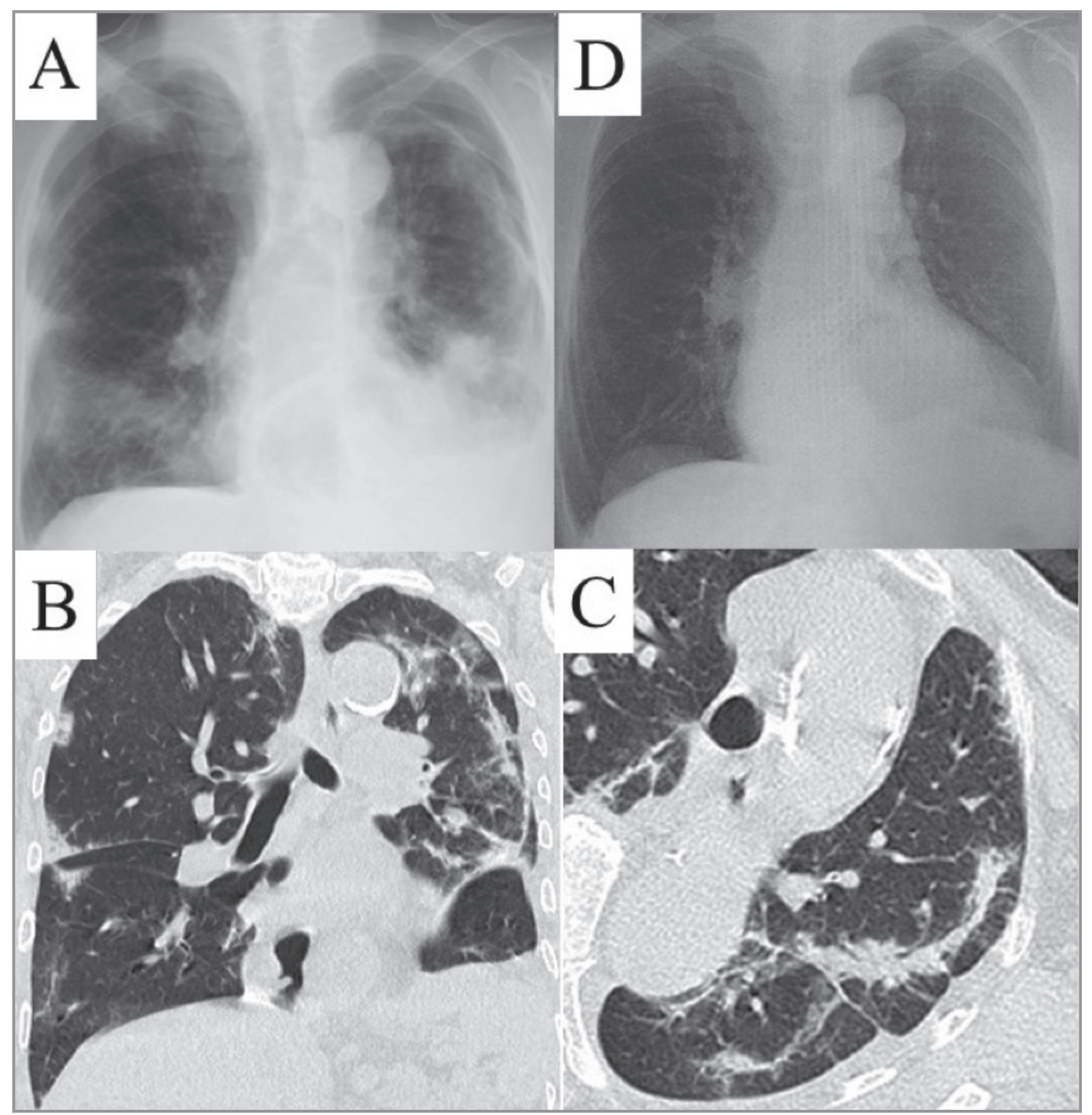

Figure 1. A curvilinear line at the lateral zone of the right lung on plain chest radiograph A. The curvilinear line in the lung field mimicking pneumothorax was revealed B-C. The subpleural curvilinear shadows disappeared on a plain radiograph two months after the start of treatment $\mathbf{D}$.

almost even on both sides, but they may show significant opacities on one side, if not unilaterally (5). If it is significant on one side, it may be difficult to differential diagnosis, but it is a disease that is usually recalled from opacities. A diagnosis is established if an increase in eosinophils in the peripheral lungs is confirmed (5). Despite very rare, linear shadows along the pleura in the peripheral lungs can present in patients with eosinophilic pneumonia. This opacity is known as subpleural curvilinear shadow $(3,4)$. It is thought that the areas where inflammation caused by eosinophils is particularly prominent are linear. The reason for the opacity along the pleura is unclear, although it may be related to the branching of lymphatic and blood circulation. In eosinophilic pneu- monia, subpleural curvilinear shadows are not observed alone and are usually accompanied by ground glass shadows and consolidation in the peripheral lungs. With the administration of corticosteroids or the natural course, ground glass shadows and consolidation disappear completely in the peripheral lungs. Subpleural curvilinear shadows disappear, even with some time lag, as observed in our patient. On plain radiographs of our patients, some curved shadows resembled a linear shadow from the parietal pleura of the lung contracted during pneumothorax. When differential diagnosis is required, chest CT scan can helpful to make a correct diagnosis. 


\section{REFERENCES}

1. Murphy JM, Schnyder P, Verschakelen J, Leuenberger P, Flower CD. Linear opacities on HRCT in bronchiolitis obliterans organising pneumonia. Eur Radiol 1999; (9): 1813-7.

2. Douglas $W W$, Tazelaar HD, Hartman TE, Hartman RP, Decker PA, Schroeder DR, et al. Polymyositisdermatomyositis-associated interstitial lung disease. Am J Respir Crit Care Med 2001; 164(7): 1182-5.

3. Kagohashi K, Ohara G, Kurishima K, Kawaguchi M, Nakayama H, Ishikawa $H$, et al. Chronic eosinophilic pneumonia with subpleural curvilinear shadow. Acta Medica (Hradec Kralove) 2011: 54(1): 45-8.
4. Saito S, Tsuneta Y, Nishiura Y, Takahashi W, Kato H, Kawai T. A case of chronic eosinophilic pneumonia with a subpleural curvilinear shadow. Nihon Kyobu Shikkan Gakkai Zasshi 1995: 33(5): 528-32.

5. Bernheim A, McLoud T. A Review of clinical and imaging findings in eosinophilic lung diseases. AJR Am J Roentgenol 2017; 208(5): 1002-10. 